\title{
Bisphosphonates Directly Inhibit the Bone Resorption Activity of Isolated Avian Osteoclasts In Vitro
}

\author{
Aldo Carano, ${ }^{\star \neq 5}$ Steven L. Teitelbaum, ${ }^{* 11}$ John D. Konsek, ${ }^{\star}$ Paul H. Schlesinger, ${ }^{*}$ and Harry C. Blair* \\ *Department of Pathology, Jewish Hospital at Washington University Medical Center, ${ }^{\ddagger}$ Washington University School \\ of Dental Medicine, St. Louis, Missouri 63110; ' Institute of Human Anatomy, University of Bari, Bari, Italy; \\ "Shriners' Hospital for Crippled Children (St. Louis Unit), St. Louis, Missouri 63131
}

\begin{abstract}
Bisphosphonates are useful in treatment of disorders with increased osteoclastic activity, but the mechanism by which bisphosphonates act is unknown. We used cultures of chicken osteoclasts to address this issue, and found that 1-hydroxyethylidenediphosphonic acid (EHDP), dichloromethylidenediphosphonic acid $\left(\mathrm{Cl}_{2} \mathrm{MDP}\right)$, or 3-amino-1-hydroxypropylidene-1,1-diphosphonic acid (APD) all cause direct dose-dependent suppression of osteoclastic activity. Effects are mediated by bone-bound drugs, with $50 \%$ reduction of bone degradation occurring at $500 \mathrm{nM}$ to $5 \mu \mathrm{M}$ of the different agents. Osteoclastic bone-binding capacity decreased by $30-40 \%$ after $72 \mathrm{~h}$ of bisphosphonate treatment, despite maintenance of cell viability. Significant inhibition of bone resorption in each case is seen only after 24-72 h of treatment.

Osteoclast activity depends on ATP-dependent proton transport. Using acridine orange as an indicator, we found that EHDP reduces proton accumulation by osteoclasts. However, inside-out plasma membrane vesicles from osteoclasts transport $\mathrm{H}^{+}$normally in response to ATP in high concentrations of EHDP, $\mathrm{Cl}_{2} \mathrm{MDP}$, or APD. This suggests that the bisphosphonates act as metabolic inhibitors. Bisphosphonates reduce osteoclastic protein synthesis, supporting this hypothesis. Furthermore, $\left[^{3} \mathbf{H}\right]$ leucine incorporation by the fibroblast, which does not resorb bone, is also diminished by EHDP, $\mathbf{C l}_{2} \mathbf{M D P}$ and APD except when co-cultured with bisphosphonate-binding bone particles. Thus, the resorption-antagonizing capacities of EHDP, $\mathrm{Cl}_{2} \mathrm{MDP}$ and $\mathrm{APD}$ reflect metabolic inhibition, with selectivity for the osteoclast resulting from high affinity binding to bone mineral. ( $J$. Clin. Invest. 1990. 85:456-461.) diphosphonates $\bullet$ Paget's disease $\bullet$ proton pump
\end{abstract}

\section{Introduction}

Bisphosphonates (diphosphonates) are compounds characterized by nonhydrolyzable P-C-P groups that bind avidly to hydroxyapatite (1). These agents are known to impact dramatically upon the skeleton, particularly as inhibitors of resorption, and are thus effective in the treatment of Paget's disease and hypercalcemia of malignancy (2). Despite the importance of

Address reprint requests to Dr. Blair, Department of Pathology, Jewish Hospital at Washington University Medical Center, 216 South Kingshighway, St. Louis, MO 63110.

Received for publication 28 November 1988 and in revised form 12 October 1989.

J. Clin. Invest.

(c) The American Society for Clinical Investigation, Inc.

$0021-9738 / 90 / 02 / 0456 / 06 \$ 2.00$

Volume 85, February 1990, 456-461 these drugs in the treatment of hyper-resorptive states, the means by which they block osteoclastic activity remains enigmatic.

Early reports suggested that the antiresorptive effects of bisphosphonates reflect their properties as inhibitors of hydroxyapatite formation and dissolution. On the other hand, direct inhibition of hydroxyapatite crystal growth by 1-hydroxyethylidene-diphosphonic acid (EHDP) ${ }^{1}$ requires a drug concentration of $2 \times 10^{-4} \mathrm{M}$, while typical absorbed doses of EHDP in treatment of Paget's disease are $\sim 0.25$ to $6 \times 10^{-5}$ $\mathrm{M} / \mathrm{kg}$ body mass. Effective serum concentrations are lower still because the drug is rapidly bound by the skeleton or eliminated in the urine (1-3). Consequently, recent studies have focused on the cellular effects of these drugs, which include inhibition of $\left[{ }^{3} \mathrm{H}\right]$ thymidine incorporation by bone marrowderived macrophages, thought to be related to osteoclasts (4), as well as effects on migration and transformation of putative osteoclastic precursors (5), all of which occur at low micromolar or nanomolar bisphosphonate concentrations.

It remains unclear, nevertheless, how these general metabolic effects relate to suppression of bone degradation and, most importantly, whether bisphosphonates target specifically to osteoclasts, as opposed to precursor cells or cells indirectly regulating resorption. To this end, we studied the effects of three representative and widely utilized bisphosphonates, EHDP, $\mathrm{Cl}_{2} \mathrm{MDP}$, and APD, on isolated chicken osteoclasts, and found that each drug impedes the bone resorbing capacity of these cells in a dose-dependent manner. This was confirmed by showing that EDHP reduces the capacity of chicken osteoclasts to acidify the cell-bone interface, a central event in bone resorption, but EHDP, $\mathrm{Cl}_{2} \mathrm{MDP}$ and $\mathrm{APD}$ have no direct, measurable effect on the activity of the vacuolar proton pump in response to exogenous ATP. In contrast, EHDP, $\mathrm{Cl}_{2} \mathrm{MDP}$ or APD suppress $\left[{ }^{3} \mathrm{H}\right]$ leucine uptake by both osteoclasts and fibroblasts that is eliminated, in fibroblasts but not osteoclasts, by the presence of bone. Thus, the selective effect of bisphosphonates on the osteoclast appears to reflect the avidity with which these drugs bind to bone and the unique capacity of this cell to degrade skeletal tissue and thus increase its exposure to the free compounds.

\section{Methods}

Unless otherwise specified, reagents were from the Sigma Chemical Co. (St. Louis, MO), and media were from Gibco Laboratories (Grand Island, NY).

1. Abbreviations used in this paper: $\alpha$-MEM: Eagle's Minimum Essential Medium, $\alpha$-modification; APD: 3-amino-1-hydroxypropylidine1,1-diphosphonic acid; $\mathrm{Cl}_{2} \mathrm{MDP}$ : dichloromethylidinediphosphonic acid; EHDP: 1-hydroxyethylidenediphosphonic acid (Didronel). 
Cell cultures. Osteoclasts were isolated from medullary bone of calcium-starved laying hens, and viable, bone binding cells purified $(95-98 \%)$ by bone-affinity overnight as described $(6,7)$. Thus, osteoclasts were continuously cultured in the presence of bone. Cells were plated in 24 or 48 well plates ( 2 and $0.5 \mathrm{~cm}^{2} /$ well, respectively) at $10^{4}$ or $5 \times 10^{3} /$ well, respectively, in $\alpha$-MEM with $10 \%$ fetal calf serum, 100 $\mu \mathrm{g} / \mathrm{ml}$ of streptomycin, $100 \mathrm{U} / \mathrm{ml}$ of penicillin, and $5 \mu \mathrm{g} / \mathrm{ml}$ of cytosine- $\beta$-D-arabinofuranoside (to suppress multiplication of non-osteoclastic contaminants). Cultures were maintained at $37^{\circ} \mathrm{C}$ in humidified air with $5 \% \mathrm{CO}_{2}$. Aliquots of osteoclasts were counted after swelling the cells in $0.2 \% \mathrm{NaCl}$ and vortexing vigorously to disaggregate the cells. For isolation, $1 \mathrm{mg}$ of $25-50-\mu \mathrm{m}$ fragments of rat bone was used per $10^{6}$ cells. Essentially all of this bone is resorbed by the cells before the start of labeled bone resorption and bone binding assays (done at $48 \mathrm{~h}$ postisolation) (6). The cells attach to the tissue culture plates during this incubation, and thus remain fixed to the plate during bone resorption and binding experiments.

Chicken fibroblasts, isolated from fetal connective tissue by collagenase digestion, were the kind gift of E. Greenfield (Jewish Hospital at Washington University Medical Center, St. Louis, MO).

Bone binding and resorption assays. Binding (8) and resorption (6) assays were performed as described. Briefly, $100 \mu \mathrm{g}$ of 35-63- $\mu \mathrm{m}$ fragments of metabolically $L-\left[4,5-{ }^{3} \mathrm{H}\right]$ proline labeled devitalized rat bone (9) were used as substrate for these assays. Bone resorption was measured as ${ }^{3} \mathrm{H}$ in supernatants of cultures $(\sim 10,000$ osteoclasts in $1 \mathrm{ml}$ of $\alpha$-MEM with $10 \%$ fetal calf serum) relative to no-cell cultures. Each experiment included independent controls from the same cell isolate to prevent small variations in cell number and activity from affecting the results. Counts per minute per microgram bone were measured by total hydrolysis of substrate $\left(6 \mathrm{~N} \mathrm{HCl}, 110^{\circ} \mathrm{C}, 24 \mathrm{~h}\right)$ and scintillation counting to allow expression of resorption per microgram bone. Cellbone binding was assayed by exposing osteoclasts precultured for $72 \mathrm{~h}$ in the presence or absence of bisphosphonates $(11 \mu \mathrm{M})$ to $\left[{ }^{3} \mathrm{H}\right]$ prolinelabeled particles for $3 \mathrm{~h}$ in standard culture conditions $\left(5 \% \mathrm{CO}_{2}, 37^{\circ} \mathrm{C}\right)$, rinsing the wells, and hydrolyzing the cell-associated material as above.

Proton transport measurement. Proton transport by osteoclasts in culture was studied by a modification of the method of Baron et al. (10), who used microscopic fluorescence localization of acridine orange to indicate localized acidification. Acridine orange is a fluorescent weak base that is concentrated in acidic vesicles and subcellular compartments, since the weak base is protonated at low $\mathrm{pH}(<7)$ and the charged (protonated) form of the dye is membrane impermeant. The protonated dye, however, does not fluoresce at the same frequency as the uncharged form $(540 \mathrm{~nm})$, and thus the quenching of fluorescence is an indicator of acid transport (protonated dye accumulation). Acridine orange also binds to DNA which, unfortunately, causes quenching of its fluorescence unrelated to acidification. We differentiate between dye $(1 \mu \mathrm{M})$ sequestered in acidic compartments and binding of dye to DNA or other cellular components by the addition of a large excess of a non-fluorescent weak base (1-15 $\mathrm{mM} \mathrm{NH}_{4} \mathrm{Cl}$ ). At these concentrations, $\mathrm{NH}_{4} \mathrm{Cl}$ increases the $\mathrm{pH}$ of acidic compartments (11), thus releasing the acridine orange, without affecting the non-pH dependent dye quenching.

These experiments were performed by placing osteoclasts, attached to glass slides (12) into $3 \mathrm{ml}$ of PBS, containing $1 \mu \mathrm{M}$ acridine orange, in cuvettes and measuring fluorescence at $540 \mathrm{~nm}$ with excitation at $468 \mathrm{~nm}$. After equilibration (2-5 min), $1-15 \mathrm{mM} \mathrm{NH}_{4} \mathrm{Cl}$ is added, reversing dye quenching that is due to sequestration of dye in acid compartments. Fluorescence of dye alone, in arbitrary units, is indicated as "total dye fluorescence," with fractions of this indicating the degree of quenching (i.e., 0.1 indicates $10 \%$ of the dye is quenched), which has been established to be proportional to proton transport (13).

Proton transport in isolated inside-out vesicles of osteoclast membranes was performed as described $(13,14)$. Vesicles were produced by homogenization of $2 \times 10^{7}$ osteoclasts in $15 \mathrm{ml}$ of $230 \mathrm{mM}$ sucrose, 40 $\mathrm{mM} \mathrm{KCl}, 5 \mathrm{mM}$ Tris, $1 \mathrm{mM}$ EGTA, $1 \mathrm{mM}$ dithiothreitol, $\mathrm{pH}$ 7.0, followed by centrifugation at $1,000 \mathrm{~g}$ for $5 \mathrm{~min}, 6,000 \mathrm{~g}$ for $15 \mathrm{~min}$, and $48,000 \mathrm{~g}$ for $30 \mathrm{~min}$. The last pellet, containing the vesicles, was resus-

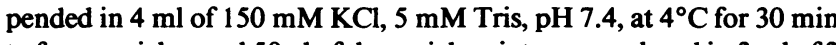
to form vesicles, and $50 \mu \mathrm{l}$ of the vesicle mixture was placed in $3 \mathrm{ml}$ of 2 $\mu \mathrm{M}$ acridine orange in the same buffer, with $5 \mathrm{mM} \mathrm{ATP}$, and $1 \mathrm{mM}$ $\mathrm{MgCl}_{2}$ was added to initiate transport, which was measured by fluorescence at $540 \mathrm{nM}$ with excitation at $468 \mathrm{~nm}$. As vesicles in this case were reformed in chloride-containing medium, valinomycin (13) was found to be unnecessary to promote vesicle acidification. This preparation contained no oligomycin-sensitive activity (not shown), and therefore that inhibitor was not routinely added. Transport was initiated with $\mathrm{MgCl}_{2}$ rather than by ATP to prevent shift of the fluorescent baseline due to $(5 \mathrm{mM})$ adenosine, a problem that does not occur if the same process is measured by differential absorbance spectrophotometry (13). Total dye fluorescence is defined as in osteoclast culture measurements (above). Gradients were collapsed with the $\mathrm{H}^{+}$ionophore nigericin at the end of each test as an internal control.

Cell survival. Number of attached cells and viability were measured by cell counting and trypan blue exclusion, and quantitative DNA content of attached cells by the ethidium bromide intercalation technique described by Karsten and Wollenberger (15). These measurements were done in parallel with resorption assays on identical tissue culture wells.

Protein synthesis. Protein synthesis was assessed using $\left[{ }^{3} \mathrm{H}\right]$ leucine incorporation, essentially as described previously (8). Briefly, cells were incubated in media supplemented with $1 \mu \mathrm{Ci} / \mathrm{ml}$ of the labeled amino acid for $6 \mathrm{~h}$, after which cells were rinsed twice with PBS, and isotope that had been incorporated into macromolecules was fixed for $30 \mathrm{~min}$ in $10 \% \mathrm{TCA}, 30 \mathrm{~min}$ in $5 \%$ TCA, and lipid soluble materials were removed with ethanol/ether $(3: 1, \mathrm{vol} / \mathrm{vol})$. Thereafter, protein was solubilized by digestion with $100 \mathrm{mM} \mathrm{NaOH}$, for scintillation counting. $\left[{ }^{3} \mathrm{H}\right]$ Leucine in supernatants was not significantly affected by the presence of bone or EHDP (not shown).

Statistics. Where an error range is given, it represents standard deviation. Unless otherwise stated, resorption and binding assays were performed in triplicate. All comparisons of data where a difference is concluded and where error ranges are shown were significant $(P=0.01$ or less).

\section{Results}

Incubation of osteoclasts with bisphosphonates directly suppressed their capacity to resorb $\left[{ }^{3} \mathrm{H}\right]$ proline labeled bone (Fig. 1). $50 \%$ inhibition was achieved with $1.5 \mu \mathrm{M}$ EHDP, $5 \mu \mathrm{M}$

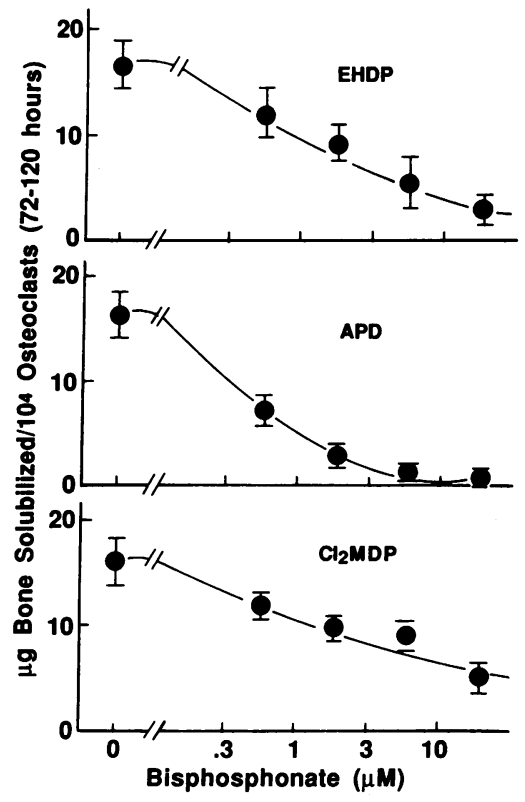

Figure 1. Bone resorption by 10,000 osteoclasts incubated with $100 \mu \mathrm{g}$ of $\left[{ }^{3} \mathrm{H}\right]$ proline labeled bone in the presence of varying concentrations of EHDP, APD, and $\mathrm{Cl}_{2} \mathrm{MDP}$ added at $0 \mathrm{~h}$. The values reflect bone resorbed between 72-120 hours of culture, as the effect has a slow onset (see Fig. 3). Mean $\pm \mathrm{SD}, n=3$ in this and succeeding figures unless otherwise noted. 
$\mathrm{Cl}_{2} \mathrm{MDP}$ and $500 \mathrm{nM}$ APD. Despite their dramatic impact on bone degradation, EHDP and $\mathrm{Cl}_{2} \mathrm{MDP}$ had only slight effects on viability, as $>80 \%$ of osteoclasts incubated with up to 16 $\mu \mathrm{M}$ of either compound remained attached, and of these $>90 \%$ excluded trypan blue, after $120 \mathrm{~h}$ of treatment (Table I). APD was somewhat more toxic, as demonstrated by 40-50\% reduction in plastic-attached osteoclasts and trypanblue exclusion between 1.6 and $12 \mu \mathrm{M}$ after $120 \mathrm{~h}$ of culture.

On the other hand, EHDP, APD, and $\mathrm{Cl}_{2} \mathrm{MDP}$ all appeared to be potent general inhibitors of the osteoclast's metabolism. Specifically, treatment with $11 \mu \mathrm{M}$ of each reduced $\left[{ }^{3} \mathrm{H}\right]$ leucine incorporation into $10 \%$ TCA-precipitable protein by $40-50 \%$ (Table II). The drugs also reduce protein synthesis by fibroblasts, particularly in the absence of bone (see below).

Bone resorption is a multistep process initiated by osteoclast-matrix attachment, and we found that $72 \mathrm{~h}$ treatment with each bisphosphonate $(11 \mu \mathrm{M})$ reduced by $30-40 \%$ the cell's capacity to bind bone (Table III). In light, however, of the $>90 \%$ suppression of resorption generally observed with these concentrations of drugs (Fig. 1), most of the inhibitory influences of these bisphosphonates could not be accounted for by their impact on cell-matrix attachment. Thus, we turned to another step pivotal to bone degradation, namely acidification of the resorptive micro-environment as osteoclasts mobilize bone mineral by vectorial $\mathrm{H}^{+}$transport (14). Using $\mathrm{NH}_{4} \mathrm{Cl}$ reversible acridine-orange uptake as a measure of proton accumulation and EHDP, which had the highest resorption inhibition to toxicity ratio (Fig. 1, Table I) as the test compound, we measured acidification by intact osteoclasts on bone. We found that $72 \mathrm{~h}$ of EHDP treatment $(1.6 \mu \mathrm{M})$ resulted in complete loss of detectable low pH compartments (Fig. 2). Exposure to $1.6 \mu \mathrm{M}$ EHDP for just $2 \mathrm{~h}$, however, did nót suppress acidification (not shown). The relatively prolonged bisphosphonate treatment (24-72 h) necessary to detect reduced proton transport by osteoclasts was also consistent with the time course of bone degradation experiments by each bisphosphonate (Fig. 3).

Table I. Effect of Bisphosphonate Concentrations on Osteoclast Viability

\begin{tabular}{lll}
\hline $\begin{array}{c}\text { Bisphosphonate } \\
\text { concentration }\end{array}$ & Plastic bound DNA & $\begin{array}{r}\text { \% Plastic bound cells } \\
\text { excluding trypan blue }\end{array}$ \\
\hline \multicolumn{1}{c}{$\mu M$} & \multicolumn{1}{c}{$\mu g /$ well } & \\
\multicolumn{1}{c}{0} & $0.68 \pm 0.06$ & $94 \pm 5$ \\
EHDP 0.5 & $0.63 \pm 0.035$ & \\
APD 0.5 & $0.53 \pm 0.012$ & ND \\
Cl ${ }_{2}$ MDP 0.5 & $0.61 \pm 0.02$ & \\
EHDP 1.6 & $0.61 \pm 0.06$ & $96 \pm 3$ \\
APD 1.6 & $0.56 \pm 0.012$ & $65 \pm 1$ \\
Cl ${ }_{2}$ MDP 1.6 & $0.63 \pm 0.05$ & $94 \pm 1$ \\
EHDP 5.6 & $0.55 \pm 0.05$ & \\
APD 5.6 & $0.38 \pm 0.025$ & ND \\
Cl ${ }_{2}$ MDP 5.6 & $0.53 \pm 0.06$ & $95 \pm 2$ \\
EHDP 16.8 & $0.53 \pm 0.015$ & $60 \pm 3$ \\
APD 16.8 & $0.23 \pm 0.18$ & $93 \pm 4$ \\
Cl ${ }_{2}$ MDP 16.8 & $0.47 \pm 0.08$ & \\
\hline
\end{tabular}

DNA attached/well and trypan blue exclusion were determined after $96 \mathrm{~h}$ of bisphosphonate incubation.
Table II. Effect of Resorption-inhibiting Concentrations of Bisphosphonates (Fig. 1) on $\left[^{3} \mathrm{H}\right]$ Leucine Uptake by Osteoclasts and on Fibroblasts in the Presence and Absence of Bone

\begin{tabular}{lcccc}
\hline & Control & EHDP & APD & $\mathrm{Cl}_{2} \mathrm{MDP}$ \\
\hline $\begin{array}{l}\text { Osteoclasts } \\
\begin{array}{l}\text { Fibroblasts } \\
\text { without bone }\end{array}\end{array}$ & $100 \pm 8.7$ & $62 \pm 5$ & $52 \pm 10$ & $63 \pm 3$ \\
$\begin{array}{l}\text { Fibroblasts and } \\
200 \mu \mathrm{g} / \mathrm{ml} \text { bone }\end{array}$ & $100 \pm 4.9$ & $36 \pm 11$ & $58 \pm 10$ & $66 \pm 2$ \\
\hline
\end{tabular}

10,000 osteoclasts isolated in the presence of bone or 100,000 fibroblasts cultured in the presence or absence of bone were exposed to 11 $\mu \mathrm{M}$ of each bisphosphonate for $72 \mathrm{~h}$, after which $\left[{ }^{3} \mathrm{H}\right]$ leucine uptake was measured during a 6-h culture interval (Methods). Addition of bone to control fibroblast cultures did not effect $( \pm 5 \%)\left[{ }^{3} \mathrm{H}\right]$ leucine incorporation. Values are expressed as percent control uptake $\pm S D$.

While these data demonstrate that EHDP blocks osteoclastic proton pump activity, they do not prove that the drug targets directly to the $\mathrm{H}^{+}$-ATPase recently shown to be responsible for acidification of the osteoclast's resorptive microenvironment (14). We addressed this issue by incubating inside-out vesicles derived from osteoclast membranes with ATP and acridine orange in the presence of 0-25 $\mu \mathrm{m}$ EHDP, and found that the bisphosphonate fails to alter ionophore-reversible dye uptake after $\mathrm{Mg}^{2+}$-mediated ATPase activation (Fig. 4). In similar experiments, $\mathrm{Cl}_{2} \mathrm{MDP}(12 \mu \mathrm{M})$ and APD $(6 \mu \mathrm{M})$, concentrations capable of inhibiting essentially all acidifying activity of whole cells at $72 \mathrm{~h}$, also failed to measurably affect the activity of the vacuolar proton pump (data not shown). Thus, these bisphosphonates reduce activity of the $\mathrm{H}^{+}$pump, and hence bone resorption, by an indirect mechanism.

Finally, we queried if the three bisphosphonates are delivered to osteoclasts via their resorptive activity, as these drugs bind avidly to hydroxyapatite (3). In the experiments illustrated in Fig. 5, either unlabeled or $\left[{ }^{3} \mathrm{H}\right]$ proline-bearing bone was preincubated in $5.6 \mu \mathrm{M}$ bisphosphonate, washed and added to osteoclast-containing cultures (i.e., only bone-bound drug was added). While each well contained the same quantities of unlabeled and radioactive matrix, the cultures in which resorption of radiolabeled bone were most inhibited were those in which the ${ }^{3} \mathrm{H}$-bearing matrix was preincubated with the bisphosphonate. In contrast, when unlabeled bone was preincubated with the drug, only partial suppression of resorption occurred. In these experiments, each cell often bound more than one particle of bone (not shown), and hence the

Table III. Effect of Bisphosphonates on Bone Binding by Plastic-bound Osteoclasts

\begin{tabular}{lcccc}
\hline & & \multicolumn{3}{c}{ Treatment } \\
\cline { 3 - 5 } & Control & EHDP & APD & Cl $_{2}$ MDP \\
\hline Bound \% & $93 \pm 1$ & $63 \pm 4$ & $63 \pm 7$ & $59 \pm 4$
\end{tabular}

10,000 osteoclasts were incubated with $11 \mu \mathrm{M}$ bisphosphonate for 72 $\mathrm{h}$ after which their capacity to bind $\left[{ }^{3} \mathrm{H}\right]$ proline labeled bone particles during the next $3 \mathrm{~h}$ was determined (Methods). 

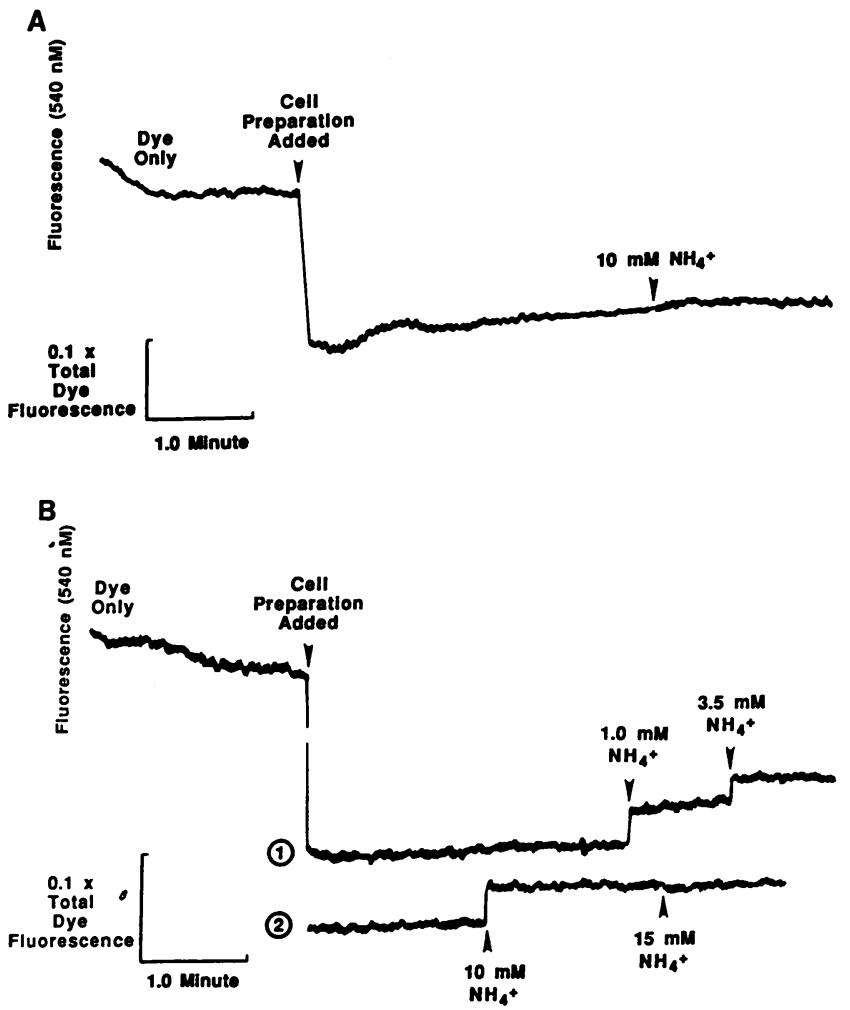

Figure 2. Ammonium-chloride-reversible acridine orange accumulation by 5,000 osteoclasts cultured $72 \mathrm{~h}$ with $200 \mu \mathrm{g}$ of bone in the presence $(A)$ or absence $(B)$ of $1.6 \mu \mathrm{M}$ EHDP. The cell preparation was placed in $1 \mu \mathrm{M}$ acridine orange in PBS, allowed to equilibrate, and $\mathrm{NH}_{4} \mathrm{Cl}$ added (11). The ratio of bone to cells was raised, relative to Fig. 1, to increase cell-bone attachment sites, which are the acidified regions (14). No reversible dye uptake was seen in the presence of EHDP $(A)$. Partial reversal of acidification occurs with 1-3.5 mM $\mathrm{NH}_{4}$ in control cells $(B$, upper trace) and complete reversal at $10 \mathrm{mM}$ (lower trace). Vertical axis indicates dye fluorescence, with a decline of 0.1 representing $10 \%$ quenching (see Methods).

partial effect of drug-treated, nonlabeled bone on the resorption of non-drug treated, labeled bone may reflect resorption of both types of particles by the same cell. In any case, it is clear from this experiment that the osteoclast-inhibiting property of each of the three bisphosphonates tested can be mediated by bone-bound drug, and that the effect is most dramatic when the drug resides on the resorptive surface. The control resorption varies slightly in Fig. $5 \mathrm{~B}$, due to batch-to-batch variation in activity of cells from various animals; however, the same batch of cells is used throughout each experiment, so that the control comparison for each drug's effect is with cells of the same batch.

This conclusion, and the known high affinity of bisphosphonates for hydroxyapatite (3), suggested to us that the apparent specificity of inhibition of osteoclasts by EHDP, $\mathrm{Cl}_{2} \mathrm{MDP}$ and APD was due to the affinity of the drugs for bone, the osteoclastic substrate, rather than an inherent high susceptibility of this particular cell to these agents. This hypothesis was tested by comparing the effects of bisphosphonates on $\left[{ }^{3} \mathrm{H}\right]-$ leucine incorporation by fibroblasts in the presence and absence of bone (Table II). It is clear that, while radioligand incorporation into TCA-precipitable protein by these nonbone resorptive cells was markedly reduced by EHDP,

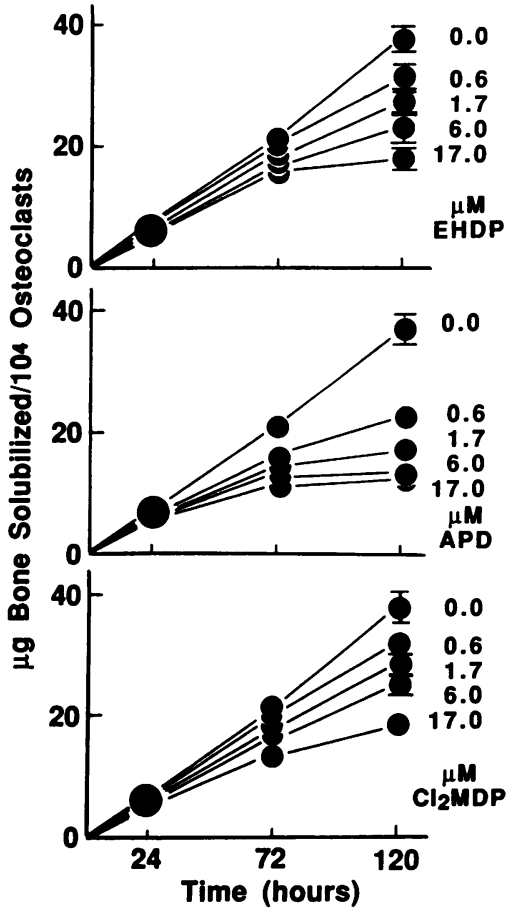

Figure 3. Time course of resorption of $100 \mu \mathrm{g}$ of $\left[{ }^{3} \mathrm{H}\right]$ proline labeled bone by 10,000 osteoclasts, as a function of EHDP, $\mathrm{Cl}_{2} \mathrm{MDP}$ or APD. Where error is not shown, symbol size exceeds $\mathrm{SD}(n=3)$.
$\mathrm{Cl}_{2} \mathrm{MDP}$ or APD in the absence of bone, the inhibition was largely reversed in the presence of mineralized skeletal matrix. The fibroblasts remained, in this case, almost uniformly unattached to the bone (not shown), suggesting that the matrix's protective effect reflects its capacity to bind the drug, thereby isolating it from the nonresorptive cells.

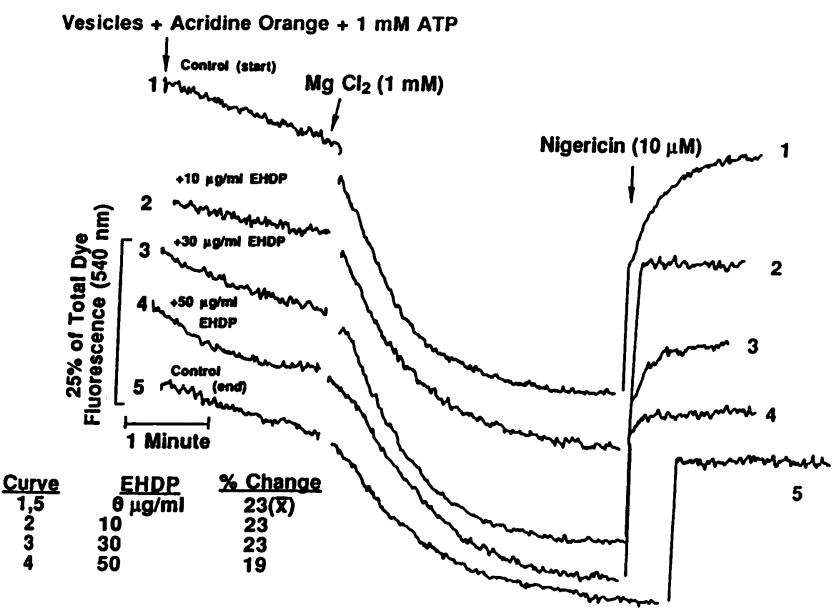

Figure 4. ATP dependent proton transport by inside-out vesicles from osteoclast membranes is unaffected by EHDP. ATP-dependent acridine orange accumulation by $50 \mu \mathrm{l}$ of vesicles (left arrow), after addition of $1 \mathrm{mM} \mathrm{MgCl}$ (second arrow), measured by quenching of fluorescence at $540 \mathrm{~nm}$ with excitation at $468 \mathrm{~nm}$, does not vary significantly at EHDP as high as $50 \mu \mathrm{g} / \mathrm{ml}(\sim 250 \mu \mathrm{M})$. Zero EHDP measurements, made before and after $\operatorname{EHDP}(10,30,50 \mu \mathrm{g} / \mathrm{ml})$ traces, bracket the values measured in the presence of drug (inset). Nigericin (right arrow), an $\mathrm{H}^{+} / \mathrm{K}^{+}$ionophore, is added at the end of each experiment to collapse the gradient, an internal control. Total dye fluorescence is defined in Methods. 

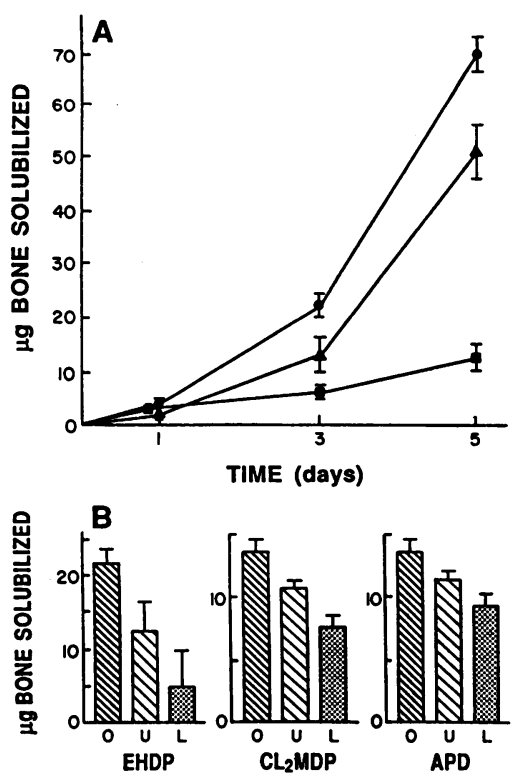

and APD on bone resorption. Bone was either untreated with drugs $(O)$ or the unlabeled $(U)$ or $\left[{ }^{3} \mathrm{H}\right]$ proline-labeled $(L)$ bone was pretreated with $5.0 \mu \mathrm{M}$ bisphosphonate as in $(A)$, and resorption measured after $72 \mathrm{~h}$. Control resorption varies $\sim 30 \%$ because different batches of cells were used to produce the graphs for EHDP and the other two drugs (see Results).

\section{Discussion}

Bisphosphonates are nonhydrolyzable analogues of pyrophosphates that block bone degradation (1) and bind avidly to hydroxyapatite, inhibiting crystal dissolution at high concentrations $(1,3)$. These drugs, because of their skeletal affinity, also serve as markers of bone remodeling and are used to treat Paget's disease and hypercalcemia of malignancy (2). These initial and most subsequent studies, which involved whole animal and explant culture experiments, clearly documented that bisphosphonates impact on osteoclasts. For example, compounds such as $\mathrm{Cl}_{2} \mathrm{MDP}$ administered to rats block both resorption of the primary spongiosa and osteoclastic activity at the periosteal surface, leading to gross abnormalities of skeletal modeling (16). Similarly, both $\mathrm{Cl}_{2} \mathrm{MDP}$ and EHDP inhibit cell-mediated bone resorption when placed in culture with mouse neonatal calvaria or when given to mice before explant preparation (17).

While administration of bisphosphonates leads to dramatic changes in osteoclastic morphology, the cellular complexity of organ culture and whole animal models precluded, using these approaches to show how the compounds block the resorptive process, or if, in fact, they target directly to osteoclasts. Some years ago we attempted to circumvent this problem by exploring the effect of bisphosphonates on the resorptive capacity of rodent macrophages, cells ontogenetically related to osteoclasts (18). Because these macrophage-based models contain only a single cell type, they permitted us to determine unequivocally whether bisphosphonates directly affect the bone-degrading ability of these cells. Interestingly, we found that while different bisphosphonates inhibit macrophage-mediated resorption by distinct and separate means, when these effects are studied in the presence of bone, they appear to involve mobilization of hydroxyapatite-bound drug.

These experiments, while provocative, are subject to the reasonable criticism that despite the probable ontogenetic relationship of macrophages and osteoclasts, macrophages are not known to participate in bone resorption in vivo. Furthermore, macrophage-mediated bone resorption is relatively inefficient, raising questions as to whether these cells degrade bone by a mechanism similar to that of osteoclasts.

The development of techniques whereby osteoclasts are isolated and maintained in tissue culture permitted us, however, to extend our studies to bona fide resorptive cells. We found that similarly to their effects on macrophages (18), bisphosphonates directly inhibit osteoclastic activity (Fig. 1). 50\% inhibition was seen at $500 \mathrm{nM}$ APD, $1.5 \mu \mathrm{M}$ EHDP, and $5 \mu \mathrm{M}$ $\mathrm{Cl}_{2} \mathrm{MDP}$. In contrast to their effects on mononuclear phagocytes, however, 24-72 h of treatment are required before osteoclastic activity is measurably suppressed (Fig. 3). Moreover and again, contrasted to the means by which $\mathrm{Cl}_{2} \mathrm{MDP}$ blocks macrophage-mediated bone resorption (4), $\mathrm{Cl}_{2} \mathrm{MDP}$ and EHDP at moderate $(<11 \mu \mathrm{M})$ doses do not kill avian osteoclasts (Table I). APD inhibits bone resorption at very low concentrations and, as the levels of the drug increase, osteoclast death occurs; in contrast to $\mathrm{Cl}_{2} \mathrm{MDP}$ and EHDP, significant APD toxicity is seen at very low concentrations.

The use of isolated osteoclasts has, in recent years, yielded major insights into the cellular mechanisms of bone resorption $(12,14)$. It is known, for example, that cell-matrix attachment is an essential step in the resorptive process (19), and we found that $11 \mu \mathrm{M}$ EHDP, $\mathrm{Cl}_{2} \mathrm{MDP}$ and APD reduce the bone-binding capacity of osteoclasts by $30-40 \%$ (Table III). Of perhaps greater interest is the bisphosphonate effect on the acidifying ability of osteoclasts. Baron and his co-workers have shown that the osteoclast-bone attachment site is an isolated acidic microenvironment (10), and we have recently documented that such acidification is pivotal to bone resorption and under the aegis of a vacuolar $\mathrm{H}^{+}$-ATPase closely resembling that of the intercalated cell of the renal tubule (14). Indeed, we found that EHDP blocks the acidifying capacity of intact osteoclasts (Fig. 2).

On the other hand, as reflected by suppression of $\left[{ }^{3} \mathrm{H}\right] l$ leucine incorporation into TCA-precipitable protein (Table II, osteoclasts), EHDP, APD, and $\mathrm{Cl}_{2} \mathrm{MDP}$ are general metabolic inhibitors of osteoclasts. These findings suggested that the agents' impact on cell-bone attachment and acidification may represent altered protein synthesis. Indeed, we noted that despite their capacity to block $\mathrm{H}^{+}$-transport by intact resorptive cells, none of the bisphosphonates reduce ATP-dependent $\mathrm{H}^{+}$ accumulation within membrane vesicles bearing the proton pump (Figs. 2 and 4; $\mathrm{Cl}_{2} \mathrm{MDP}$ and APD are not shown). Thus, it appears that while bisphosphonates have impact on physiological events central to the resorptive process, these effects are a consequence of general inhibition of cellular metabolism.

In light of these findings, we queried whether the inhibitory effects of EHDP, $\mathrm{Cl}_{2} \mathrm{MDP}$, and APD on protein synthesis are confined to the osteoclast, and found that fibroblasts are similarly affected (Table II, fibroblasts without bone). At first sight, these observations may stand in contrast to the relative selectivity of the drugs for the skeleton, but such is not the case. It appears, in fact, that it is the avidity with which bisphosphonates bind to bone-mineral that leads to their cell-selective properties. Jung et al. found that at solution concentrations as 
low as $1 \mu \mathrm{g} / \mathrm{ml}, 50-100 \mathrm{mM}$ of EHDP are bound per gram of hydroxyapatite in $<24 \mathrm{~h}$ (3). Thus, the skeleton serves as a binding substrate for bisphosphonates, removing them from solution and preventing toxicity to other cell systems in vivo. In support of this conclusion, the toxic effect on non-bone binding fibroblasts is reversed by the presence of bone matrix (Table II, fibroblasts with bone). On the other hand, we now know that the osteoclast enjoys the unique ability to attach to and degrade bone mineral in an isolated microenvironment. A reasonable hypothesis would, thus, hold that $\mathrm{EHDP}, \mathrm{Cl}_{2} \mathrm{MDP}$, and APD are released pari passu with mineral mobilization, accumulating locally within the resorptive space at levels sufficient to inhibit osteoclastic bone degradation, a conclusion supported by experiments in which resorption is most effciently reduced by pretreatment of ${ }^{3} \mathrm{H}$-labeled but not unlabeled bone with EHDP (Fig. 5). The inhibitory effects confined to osteoclasts in vivo would therefore reflect the agent's affinity to bind to bone mineral, as well as its toxicity to the cell's resorptive apparatus.

\section{Acknowledgments}

This work was supported by National Institutes of Health grants AM-32788 (to Dr. Teitelbaum), and AR-01031 (to Dr. Blair), and a grant from the Shriner's Hospital for Crippled Children (St. Louis Unit).

\section{References}

1. Fleisch, J., R. G. G. Russell, and M. D. Francis. 1969. Diphosphonates inhibit hydroxyapatite dissolution in vitro and bone resorption in tissue culture and in vivo. Science (Wash. DC). 165:1262-1264.

2. Johnston, C. C., R. D. Altman, R. E. Canfield, G. A. M. Finerman, J. D. Taulbee, and M. C. Ebert. 1983. Review of fracture experience during treatment of Paget's disease with etidronate disodium (EHDP). Clin. Orthop. 172:186-194.

3. Jung, A., S. Bisaz, and H. Fleisch. 1973. The binding of pyrophosphate and two diphosphonates by hydroxyapatite crystals. Calcif. Tissue Res. 11:269-280.

4. Cecchini, M. G., R. Felix, H. Fleisch, and P. H. Cooper. 1987. Effect of bisphosphonates on proliferation and viability of mouse bone marrow-derived macrophages. J. Bone Miner. Res. 2:135-142.

5. Lowik, C. W. G. M., G. van der Pluijm, L. J. A. van der WeePals, H. B. van Treslong-de Groot, and O. L. M. Bijvoet. 1988. Migration and phenotype transformation of osteoclast precursors into mature osteoclasts: the effect of a bisphosphonate. J. Bone Miner. Res. 3:185-192.
6. Blair, H. C., A. J. Kahn, E. C. Crouch, J. J. Jeffrey, and S. L. Teitelbaum. 1986. Osteoclasts resorb the organic and inorganic components of bone. J. Cell Biol. 102:1164-1172.

7. Zambonin-Zallone, A., A. Teti, and M. V. Primavera. 1982. Isolated osteoclasts in primary culture: First observations on structure and survival in culture media. Anat. Embryol. 165:405-415.

8. Bar-Shavit, Z., S. L. Teitelbaum, and A. J. Kahn. 1983. Saccharides mediate the attachment of rat macrophages to bone in vitro. J. Clin. Invest. 72:516-525.

9. Teitelbaum, S. L., C. C. Stewart, and A. J. Kahn. 1989. Rodent peritoneal macrophages as bone resorbing cells. Calcif. Tissue Int. 27:255-261.

10. Baron, R., L. Neff, and P. J. Courtoy. 1985. Cell-mediated extracellular acidification and bone resorption. Evidence for a low pH resorbing lacuna and localization of a $100-\mathrm{kD}$ lysosomal membrane protein at the osteoclastic ruffled border. J. Cell Biol. 101:2210-2222.

11. DeDuve, C., T. DeBarsy, B. Poole, A. Trouet, P. Tulkens, and F. van Hoof. 1974. Lysosomotropic agents. Biochem. Pharmacol. 23:2495-2531.

12. Teti, A., H. C. Blair, S. L. Teitelbaum, A. J. Kahn, C. Koziol, J. Konsek, A. Zambonin-Zallone, and P. H. Schlesinger. 1989. Cytoplasmic $\mathrm{pH}$ regulation and chloride/bicarbonate exchange in avian osteoclasts. J. Clin. Invest. 83:227-233.

13. Gluck, S., and Q. Al-Awqati. 1982. The proton translocating ATPase responsible for urinary acidification. J. Biol. Chem. 257:9230-9233.

14. Blair, H., S. Teitelbaum, R. Ghiselli, and S. Gluck. 1989. Osteoclastic bone resorption by a polarized vacuolar proton pump. Science (Wash. DC). 245:855-857.

15. Karsten, U., and A. Wollenberger. 1977. Improvement in the ethidium bromide method for the direct fluorometric measurement of DNA and RNA in cell and tissue homogenates. Anat. Biochem. 77:464-470.

16. Schenk, P., and W. A. Merz. 1973. Effect of ethane-1-hydroxy1,1-diphosphonate (EHDP) and dichloromethylene diphosphonate $\left(\mathrm{Cl}_{2} \mathrm{MDP}\right)$ on the calcification and resorption of cartilage and bone in the tibial epiphysis and metaphysis of rats. Calcif. Tissue Res. 11:196214.

17. Reynolds, J. J., C. Minkin, D. B. Morgan, D. Spycher, and H. Fleisch. 1972. The effect of two bisphosphonates on the resorption of mouse calvaria in vitro. Calcif. Tissue Res. 10:302-313.

18. Reitsma, P. H., S. L. Teitelbaum, O. L. M. Bijvoet, and A. J. Kahn. 1982. Differential action of bisphosphonates (3-amino-1-hydroxypropylidene)-1,1-bisphosphonate (APD) and disodium dichloromethylidene bisphosphonate $\left(\mathrm{Cl}_{2} \mathrm{MDP}\right)$ on rat macrophage-mediated bone resorption in vitro. J. Clin. Invest. 70:927-933.

19. Marchisio, P. C., D. Cirillo, L. Naldini, M. V. Primavera, A. Teti, and A. Zambonin-Zallone. 1984. Cell substratum interaction of culture avian osteoclasts is mediated by specific adhesion structures. $J$. Cell Biol. 99:1696-1705. 